\title{
The Human Rights Council in a nutshell
}

Study of the human anatomy, quite clearly, starts with an analysis of the body as a whole. It is not possible to conjecture what lies within a body if there is no understanding of the overall body being studied. Insofar as the Human Rights Council is concerned, this will be done succinctly based on an overall description of the Council and its main mechanisms. The aim of this chapter is to offer some general considerations that are necessary to understand their main features.

The Human Rights Council (The Council) was established by the United Nations (UN) General Assembly (The Assembly) in its Resolution $60 / 251$ of 15 March 2006 to replace the Commission on Human Rights (The Commission). Its status, which is supposed to be reviewed on a regular basis, is that of a subsidiary organ of the General Assembly.

It is composed of 47 Members which are elected directly and individually by secret ballot by the majority of the members of the Assembly. The Members of the Council serve for a period of three years and are not eligible for immediate re-election after two consecutive terms. Candidates are expected to make voluntary pledges and commitments reflecting their contribution to the promotion and protection of human rights, which are published on the website of the General Assembly. Members are requested to uphold the highest standards in the promotion and protection of human rights. The Assembly by a two-thirds majority present and voting may suspend the rights of membership of a Member that commits gross and systematic violations of human rights.

The Council meets regularly throughout the year for a total duration of no less than 10 weeks. Three regular sessions are thus scheduled every year, in February/March (the Main Session, as it is attended by government high officials in its High-level Segment of three days), June/ July and September. At the request of a member of Council with the 
support of at least one-third of the membership, namely a total of 16 States, the Council may meet in the context of Special Sessions.

The Council upon its establishment has inherited the mandates, mechanisms, functions and responsibilities of the Commission which it has assumed, reviewed, improved and rationalized by way of its Institutions-building Package comprising Council Resolutions 5/1 and $5 / 2$, adopted one year after the holding of its first session on 18 June 2007. Resolution 16/21 adopted at the end of the review of its work and functioning five years after its establishment on 15 March 2011 is to be added to this list of basic documents.

The Council's functions and responsibilities are very broad and relate inter alia to the promotion of all human rights and fundamental freedoms for all people, without distinction of any kind and in a fair and equal manner; the consideration of violations of human rights, including gross and systematic violations; and the effective coordination and the mainstreaming of human rights within the UN system.

Its work is based on the principles of universality, impartiality, objectivity and non-selectivity, constructive international dialogue and cooperation with a view to enhancing the promotion and protection of all human rights, as well as civil, political, economic, social and cultural rights, including the right to development.

Its working methods are expected to be transparent, fair and impartial and to enable dialogue, be results-oriented and allow for subsequent follow-up discussions on recommendations and their implementation. They should also allow for substantive interaction with Special Procedures and mechanisms.

In order to achieve the goals assigned to it, the Council promotes human rights education and learning as well as advisory services, technical assistance and capacity-building, serves as a forum for dialogue on thematic issues on all human rights, makes recommendations to the Assembly for the further development of international law in the field of human rights, promotes the full implementation of human rights obligations undertaken by States and follow-up to the goals and commitments related to the promotion and protection of human rights emanating from UN Conferences and Summits, undertakes a Universal Periodic Review (UPR), contributes through dialogue and cooperation to the prevention of human rights violations, responds 
promptly to human rights emergencies and makes recommendations with regard to the promotion and protection of human rights.

The Council also assumed the role and responsibilities of the Commission regarding the work of the Office of the UN High Commissioner for Human Rights and inherited from it a system of Special Procedures, expert advice and a Complaints Procedure which it delineated in its Resolution 5/1.

The Council works in close cooperation with governments, regional organizations, national human rights institutions and civil society. It applies the rules of procedures established for committees of the Assembly, as complemented by the rules developed in its Resolution $5 / 1$ and in practice. The participation of and consultation with observers, including States that are not members of the Council, specialized agencies, other intergovernmental organizations and national human rights institutions (NHRIs), as well as non-governmental organizations (NGOs), are well established. This work is based on arrangements like the Economic and Social Council Resolution 1996/31 of 25 July 1996 as well as practices observed by the Commission, and ensures the most effective contribution of these entities.

The Council submits an annual report to the Assembly. In accordance with the Assembly Resolution 65/281 of 17 June 2011, the agenda item entitled 'Report of the Human Rights Council' is allocated to the plenary of the Assembly and to the Third Committee. The President of the Council (The President) presents the Council Annual report in his/ her capacity as President to the plenary of the Assembly and the Third Committee. An interactive dialogue is organized with him/her at the time of the presentation of the report to the Third Committee.

\subsection{The UPR mechanism}

Upon its creation, the UPR represented a new and unique feature of the human rights architecture. The UPR, which is based on objective and reliable information, enables the fulfilment by each Member State of the United Nations of its human rights obligations and commitments to be reviewed in a manner that ensures universality of coverage and equal treatment with respect to all States. It is a cooperative mechanism based on an interactive dialogue with the full involvement of the country concerned. 
Since the inception of the UPR, with no exception, all UN Member States have been reviewed by the Council (see the calendar of UPR Review for the third UPR Cycle at www.ohchr.org). The periodicity of the review for the first cycle was four years, and for the second and subsequent reviews it was four and a half years. During the first cycle, 48 States were reviewed per year. As from the second cycle onwards, 42 States were reviewed per year.

The consideration of these States takes place during three sessions of two weeks each of the UPR Working Group. The Working Group is composed of the 47 Members of the Council and is chaired by the President. Although the working modalities and procedures of the Working Group resemble in every respect those of the Council, the two should not be confused as the Working Group remains a subsidiary body of the Council. This being stated, the UPR is a universal mechanism with the Council being involved in it heavily at every step of the procedure.

Each review is based on three documents called 'reports':

- The first one ${ }^{1}$ is presented by the State itself (although it is usually in a written format, it can be also done in an oral manner, as has been done on an exceptional basis).

- The second and third ones ${ }^{2}$ are presented by the Office of the High Commissioner for Human Rights (OHCHR).

The second report combines the information provided by treaty bodies, Special Procedures and other official UN documents.

The last one is a summary of 'additional, credible and reliable' information provided by national human rights institutions and nongovernmental organizations. If there is an NHRI of the State under review that is accredited as being in full compliance with the Paris Principles, ${ }^{3}$ it benefits from a separate section in this report.

The UPR is a peer-review mechanism. Accordingly, only States may participate in the interactive dialogue organized by the Working

\footnotetext{
1 Which does not exceed a number of words corresponding to 20 pages.

2 Which do not exceed a number of words corresponding to 10 pages each.

3 Usually referred to as A-status NHRI.
} 
Group. Other stakeholders may attend the review without the possibility of taking the floor.

For each review a troika of three rapporteurs is selected by drawing of lots among the members of the Council and from different regional groups. They are formed to facilitate each review, in particular the preparation of the report of the Working Group. OHCHR provides the necessary assistance to the troikas.

A complex process was set into motion in order to guide the selection of each troika. It includes the following elements:

- The country concerned may request that one of the rapporteurs be from its own regional group.

- It may also request the substitution of a rapporteur but only on one occasion.

- A rapporteur may request to be excused from participation in a specified review process.

Member and Observer States may transmit issues or questions prior to the review to the concerned State to facilitate and focus the review.

Since the start of the second UPR cycle, the duration of the review has been three and a half hours, of which one-third is made available to the State under review. The modalities for the establishment of lists of speakers are quite complex since they require all interested parties to register with the Secretariat during the week preceding the UPR Working Group session. Upon its closure at 6 p.m. on the Thursday, the Secretariat arranges the list by alphabetical order. The following day, the Council Bureau meets and its members proceed with the drawing of lots for the first speaker for each item on the list.

All those inscribed on the lists of speakers are entitled to speak. Given that the time set aside for each review is exactly the same and cannot under any circumstances be extended, the speaking time per speaker may be significantly reduced. In practical terms speaking time is often approximately one minute.

At the end of the review by the Working Group, a report is prepared. It includes all recommendations made by all of the speakers. Only those 
recommendations made orally in the context of the public meeting are included. Should the speaker be interrupted before the end of his/her statement, the part of the recommendations or statement not delivered formally is not included in the report.

The State under review must identify the recommendations that enjoy its support. All of the others are considered to be noted. In other words those recommendations are not accepted and in certain instances are utterly rejected by the State under review, although UN terminology does not use such terms. Although an inventive terminology may be used, the Council proceeds on the assumption that there are only two categories of recommendations. ${ }^{4}$ The States under review may decide to inform the Working Group about its decision at any point in time, either at the Working Group or at the Council plenary level. The latest moment for this is when the final outcome of its review is adopted by the Council.

The final outcome of the review is adopted by the plenary of the Council. The Council dedicates a one-hour segment to each State under review. It is divided in three parts of 20 minutes each. The State under review is provided with 20 minutes which it may organize as it wishes. The Council Members and Observers also have 20 minutes. The list of speakers for the second segment is organized by drawing of lots at the Bureau level, it being understood that those which cannot speak may have their written statements posted on the Internet.

Contrary to the UPR Working Group peer-review modalities, the plenary of the Council proceeds based on its own working methods, thus enabling everyone to speak. Hence, the other stakeholders, namely NHRIs and NGOs, are provided with the possibility of commenting on the outcome of the review and are also set aside a total time of 20 minutes. The list of speakers for other stakeholders is organized on a first-come first-served basis, it being understood that the national NHRI when it exists will always speak first.

From the second review onwards, the reviews were expected to focus on the implementation of the preceding cycle. Additionally, the Council considers the UPR under its agenda item 6, during which all stakeholders may participate and comment on the mechanism itself.

4. Para. 32 of HRC Resolution 5/1. 
The efficiency and effectiveness of the UPR has been applauded by all. Despite its flaws linked to the number and nature of the recommendations made during a relatively short process, there is a general recognition that the universality of this mechanism combined with the cooperative and constructive nature of the dialogue make it a very powerful tool. A lot was said, and unsaid, about the UPR but the assessment that it is one of the most, if not the most, successful Council's features is shared by all.

Almost all stakeholders have expressed their firm belief that it serves as a triggering mechanism enabling significant progress to be made at the domestic level. What often goes unnoticed is the 'psychology' of the UPR according to which States under review often feel the pressure of supporting at least the same percentage of recommendations as their neighbours or members of the groups they belong to. This average is about two-thirds, which is pretty high. Accordingly, States are in most cases led to support more recommendations that they would have anticipated initially. This immediately provides an entry point for all stakeholders to enter into a process of dialogue and implementation at the domestic level.

Another undeniable positive impact of the UPR is that States under review are eager to cooperate with those concerned at the domestic level with a view to implementing specific UPR recommendations. It is rare that the same openness exists for other mechanisms. This leads to the striking remark that national authorities may be reluctant to engage in discussing the necessary follow-up to the recommendations of Special Procedures or treaty bodies, whereas they may have absolutely no difficulty in doing so for similar or comparable recommendations made under the UPR process.

The UPR may thus be considered as a process that prioritizes action over quasi-legal consideration. It may be far more superficial but it is more likely to secure concrete results at the domestic level.

Lastly, also largely unnoticed is the fact that the UPR represents the most comprehensive and objective mapping of the human rights situation in the world. Since all States participate in the reviews over a period of four and a half years, it is the broadest and most comprehensive assessment which can be anticipated at the international level without being suspected of its partiality. There are, however, two shortcomings. The first is that this applies over a period of four and a half years 
rather than being on an annual basis and the second is that the related documentation cannot yet be condensed into a user-friendly report.

\subsection{Special Procedures}

A number of individuals or groups have been appointed to serve as Special Procedures mandate holders. All of the special rapporteurs are individual experts or working groups composed of five experts. All are independent and serve in their personal capacity. They contribute to the development of the international understanding of thematic or country situations, they conduct thematic studies, they undertake country visits and they also send communications to concerned governments when allegations of violations or abuses have been brought to their attention. They engage in promotional activities such as convening seminars, participating in conferences and providing advice for technical cooperation.

Mandate holders report to the Council on a yearly basis on the implementation of their mandate or at another time which the Council may deem appropriate. They deploy every possible activity to fulfil their mandates but do not receive a salary which makes this function a challenging one. Mandate holders consult all concerned, participate in conferences, organize seminars and/or study thoroughly the matters at stake with a view to providing the Council with the most accurate description of current or future trends. The modus operandi of the Special Procedures is based on the initiation, with the assistance of the Office of the High Commissioner for Human Rights, of country visits to analyse the human rights situation at the national level and report back to the Council. States are encouraged to extend standing invitations to all thematic Special Procedures. By doing so they announce their permanent willingness to accept requests for visits from all Special Procedures. ${ }^{5}$

Special Procedures may also intervene directly with governments concerning allegations of violations of human rights that come within their mandates by means of letters which include urgent appeals and

\footnotetext{
5 As of 16 October 2019, 121 Member States and one non-Member Observer had extended standing invitations to Special Procedures. The updated list is available at https://spinternet.ohchr. org/_Layouts/SpecialProceduresInternet/StandingInvitations.aspx. In 2019, 50 Mission Reports were submitted to the Council.
} 
other communications. ${ }^{6}$ Summaries of all communications received as well as responses are brought to the attention of the Human Rights Council on a yearly basis.

Special Procedures mandates are usually compartmentalized into two categories: at the time of writing of this Anatomy, there coexisted 46 thematic and 12 country mandates. All mandate holders are, however, bound by the same rules and practices, and their participation in the Council work follows the same procedures.

The selection of mandate holders was refined and conceptualized in the Council Resolutions 5/1 and 16/21. When nominating, selecting and appointing mandate holders, emphasis is placed on the expertise, experience, independence, impartiality, personal integrity and objectivity of the candidates. A Consultative Group composed of five State representatives selected by the five Regional Groups of the United Nations, although serving in their personal capacity, considers all applications, a list of which is publicized on line. Candidates may be nominated by governments, regional groups, international organizations, the OHCHR, NHRIs and NGOs, and by individuals.

A careful selection process is set into motion that includes interviews of the shortlisted candidates by the Consultative Group. The selection follows a three-tiered approach. Upon receipt of the recommendations of the Consultative Group, the Council President engages in consultations with all States and others, particularly regional coordinators. Upon completion of the consultations, the President issues a public list of candidates. The appointment of the mandate holders is completed upon the subsequent approval of this list by the Council. In case of difficulty with the selection of a particular person as a mandate holder, all appointments are postponed to a later stage during the session or the intersessional period.

The tenure of mandate holders in a given function cannot be longer than six years. There is a general rule of non-accumulation of human rights functions, which implies that a Special Procedure mandate holder cannot hold comparable functions in the UN system or in other international organizations. Individuals holding decision-making posi-

6 In 2018, Special Procedures sent 655 communications to countries and other actors. They conducted 84 visits in all regions of the world. They submitted a total of 181 reports, attended more than 90 forums or consultations and issued 441 press releases or comparable products. 
tions in a government, in any other international organization or entity such an NHRI or an NGO are excluded from the selection process because of a conflict of interest. Mandate holders are not paid and act in their personal capacity.

Further to the Code of Conduct included in Council Resolution 5/2, States are expected to: 'cooperate with and assist Special Procedures in the performance of their tasks'. Conversely, it is incumbent on mandate holders to exercise their functions in accordance with their mandates and in compliance with the Code of Conduct.

Given the continuing expansion in the number of Special Procedures mandates, the need was felt to initiate a formal process of coordination by the establishment of a Coordination Committee of Special Procedures. The mandate of the Committee includes enhancing the effectiveness and independence of mandate holders, raising the concerns of mandate holders in discussions of the Human Rights Council, proactively identifying issues of concern to groups of mandates and facilitating joint action on cross-cutting issues or issues of shared concern, exchanging information and facilitating the sharing of experience concerning methods of work among mandate holders, identifying innovative ways to raise awareness about Special Procedures and their work, encouraging States to cooperate with Special Procedures, and proposing a draft agenda for the Annual Meeting of the Special Procedures, which is organized on a yearly basis.

The reports of the Special Procedures are considered in the context of interactive dialogues with the Council. Such dialogues take the form of an introduction by the concerned mandate holders followed by a series of questions and comments to which he/she may respond on the spot or at the end of the list of speakers. All stakeholders may participate in the process but the contribution by NGOs is limited to a specific amount of time. ${ }^{7}$ For time-management reasons, the consideration of thematic reports is, at present, clustered into groups of two mandates at a time.

Special Procedures may also be invited on an ad hoc basis to participate in Council proceedings as panellists. When Special Sessions are being held, a representative of the Special Procedures ${ }^{8}$ takes the floor immediately after the High Commissioner to frame the discussion.

7 Fifteen minutes for individualized dialogues, 30 minutes for clustered dialogues.

8 Normally a representative of the Coordinating Committee. 
The growing number of mandates is often mentioned as an impediment to their effectiveness and visibility. It is, however, fair to observe that the world is shaped by human beings and thus faces an increasing number of challenges, the nature of which makes it necessary to have specific and focussed lenses on any given situation. The landscape continuously changes and that which is not of specific urgency today may become a priority tomorrow, and vice versa. Accordingly, the prospects for rationalizing the system of Special Procedures look quite dim, whereas a possible expansion of that system to include new activities requiring attention from the human rights system seems unfortunately high. How to respond to the challenges faced by the Council in dealing with an increasing number of country or thematic situations while shaping better the system of Special Procedures is thus an immense challenge, the responses to which remain to be identified.

The system of Special Procedures is sophisticated and able to respond to thematic or country-specific emergencies. It concerns a large variety of rights and freedoms and enables rich discussions that are not necessarily always without tension. The richness of the recommendations, the flexibility of the system, the independence of the mandate holders, their ability to conduct field visits and organize consultations on a variety of subjects and the high number of initiatives conducted every year, are highly commendable and considered as key to the Human Rights Council activity. In short, they provide the Council with a sense of accomplishment and meaning.

This is not altered by the fact that the high number of procedures generates difficulties of an organizational nature and does not enable the Council to give due credit and appropriate timing to their work. Whatever the complexity of these issues, they eventually have to be dealt with in the context of the efficiency process which is described below. ${ }^{9}$

\subsection{Commissions of inquiry, commissions on human rights, fact-finding missions and other ad hoc investigations}

In addition to the activities of Special Procedures mandate-holders, some particularly grave violations of human rights and international

9 See Chapter 7, Section 7.2. 
humanitarian law require the urgent intervention of the Council. Such crises can be abrupt and may trigger a prompt response from the Council, which may vary from an analysis of the facts to some form of identification of those responsible for violations and crimes. The shape of each mandate differs but there are some commonalities which are emerging with time. In the early years of the Council, such mandates did not follow an easily defined pattern, with scope, composition and nature varying from one case to the other. More recently, despite a noted inventiveness in the terminology, the Council has de facto started a process of harmonization of their terms of reference.

These investigation mechanisms are usually composed of three independent, international experts. They are normally appointed by the Council President, but the High Commissioner may be tasked to do so too and act as an interface with the Council. They are usually requested to establish the facts and circumstances of the alleged violations and abuses with a view to ensuring accountability for perpetrators, justice for the victims and an end to impunity. They are also tasked to formulate recommendations to the Council, in particular as to whether the alleged facts constitute international crimes or war crimes and what accountability measures can be taken. In addition, they are expected to engage with the concerned authorities or other international actors with a view to providing support and the expertise to secure the immediate improvement of the human rights situation.

They are usually asked to report back orally at the next regular Council session after their appointment and in a written manner in the subsequent ones. The duration of their mandates is one year. However, if the grave human rights situation on the ground continues, it is not uncommon for the existence of these mechanisms to be prolonged on a yearly basis for an unspecified duration.

At the time of completion of this Anatomy there were six such mechanisms in place (see Appendix I). Their reports are often considered the highlights of the Council session and the subject of intense media reporting with specific focus on their conclusions. Their impact on the rest of the UN systems is not to be neglected. 


\subsection{The Human Rights Council Advisory Committee and the Complaints Procedure}

At the time of the abolishment of the Commission on Human Rights there existed two other important mechanisms advising it, namely the Sub-Commission on the Promotion and Protection of Human Rights and the so-called 1503 procedure. ${ }^{10}$ The former provided advice to the Commission on a whole range of issues through the preparation of studies and reports as well as the consideration of matters in a public format. It also considered country situations, at least those that were not being dealt with by the Commission. In its last years of activities it was, however, deprived of the ability to adopt country-specific resolutions. ${ }^{11}$

The 1503 procedure was established to enable the Commission to examine, in a confidential manner, a consistent pattern of reliably attested violations of human rights and fundamental freedoms occurring in any country of the world. It is the oldest human rights complaint mechanism under the UN system.

When the Assembly established the Human Rights Council to replace the Commission, even if it maintained the system of Special Procedures as it was, it did not proceed in the same way insofar as the Sub-Commission and the 1503 procedure were concerned. The Assembly simply referred to the need to maintain expert advice and a Complaints Procedure. This implied that the Council had to conceptualize new systems that would not necessarily replicate the terms or mandates of these two mechanisms. Likewise, the former SubCommission's advisory bodies ${ }^{12}$ were detached from the Committee and replaced by Forums ${ }^{13}$ responding directly to the Council.

By way of Sections III and IV of the Council Resolution $5 / 1$, the Council established, after lengthy negotiations, the Human Rights Council Advisory Committee and the Complaints Procedure.

\footnotetext{
10 See ECOSOC Resolution 1503 (XLVII) of 27 May 1970.

11 See paragraph 52 of Commission's decision 2000/109 of 26 April 2000.

12 The Working Groups on Indigenous Populations; Contemporary Forms of Slavery; and Minorities and the Social Forum.

13 The Working Group on Contemporary Forms of Slavery's functions and responsibilities were taken up by a new mandate of the Special Rapporteur on Contemporary Forms of Slavery, including their causes and consequences.
} 


\subsubsection{The Human Rights Council Advisory Committee}

The Advisory Committee (the Committee) was established to serve as a 'think-tank' for the Council.

The Committee is composed of 18 experts serving in their personal capacity elected by the Council in secret ballot from a list of candidates, each of them proposed or endorsed by a UN Member State. The system is thus fundamentally different from that of the selection of Special Procedures through a three-tier process. Elections take place at the Council level, and the vote is secret if the number of candidates exceeds the number of seats allocated to each region. ${ }^{14}$

Provisions similar to those governing the system of Special Procedures exist insofar as the principles of non-accumulation of functions and that of conflict of interest are concerned. Members serve for a period of three years. They are eligible for re-election once. This implies that a member serves for a maximum of six consecutive years, as is the case for members of the Council or Special Procedures mandate holders. A former member may however be a candidate again after a one-year gap.

The functions of the Committee are clearly described as aiming at providing expertise to the Council in the manner and form requested by the Council, focussing mainly on studies and research-based advice. More importantly, such expertise may only be rendered upon the request of the Council and in compliance with its resolutions and under its guidance. It is also explicitly mentioned that the Committee should not adopt resolutions or decisions. It may however propose within the scope of the work set out by the Council, for the latter's consideration and approval, suggestions for further enhancing its procedural efficiency as well as further research proposals within the scope of the work set out by the Council.

The former Sub-Commission advisory bodies were detached from the Committee and replaced by Forums responding directly to the Council. By depriving the Committee of the ability to adopt decisions or resolutions, the Council triggered a margin of uncertainty insofar as the Committee's raison d'être and working modalities were concerned. For example, even if the Committee must follow the Council's requests,

14 The geographic distribution is as follows: African States, 5; Asian States, 5; Eastern European States, 2; Latin American and Caribbean States, 3; and Western European and other States, 3. 
the Council is not specifically requested to respond to any responses, suggestions, studies or reports emanating from the Committee. The 2011 review intended to clarify this aspect by requiring the Council to strengthen its interaction with the Committee and engage more systematically with it through work formats such as seminars and panel working groups and sending feedback on the inputs of the Committee. The Council is also requested to clarify the mandates given to the Committee. The dates of the two annual one-week sessions of the Committee were also rescheduled to bring them closer to those of the Council in the expectation that this will enable proper interaction. The Committee is also invited to interactively dialogue with the Council.

Over the years, both the Advisory Committee and the Council have intensified their relationship through formal meetings between the plenary of the former and the Bureau of the latter. Letters were sent to the Council President, including proposals for new activities, studies and research. The responses to such letters are, however, left to the individual initiatives of Member States which may or may not trigger a response to these suggestions or more often than not propose entirely new subjects for the Committee's consideration.

This management hiatus, which it is hoped will be overcome sooner or later, should however not hide the importance of the Committee, which has played a leading role in drafting instruments later revisited and adopted or considered by the Council. It has also submitted an impressive number of studies and amount of research for the Council's consideration. The mandates which the Council has given it are of importance ${ }^{15}$ and its proposals for new action have been considered of great value. ${ }^{16}$

15 The following studies have been entrusted to the Human Rights Council Advisory Committee. National policies and human rights: Contribution Of Development To The Enjoyment Of All Human Rights; The Negative Effects Of Terrorism On The Enjoyment Of All Human Rights; Activities Of Vulture Funds And Their Impact On Human Rights; Negative Impact Of The Non-Repatriation Of Funds Of Illicit Origin On The Enjoyment Of Human Rights; Regional Arrangements For The Promotion And Protection Of Human Rights; A Global Call for Concrete Action for the Total Elimination of Racism, Racial Discrimination, Xenophobia and Related Intolerance and the Comprehensive Implementation of and Follow-up to the Durban Declaration and Programme of Action; The Role Of Technical Assistance And Capacity-Building In Fostering Mutually Beneficial Cooperation In Promoting And Protecting Human Rights; New and Emerging Digital Technologies and Human Rights; Current Levels of Representation of Women in Human Rights Organs and Mechanisms; and Importance of a Legally Binding Instrument on the Right to Development.

16 Such research proposals relate to regional human rights regimes, youth human rights and social cohesion, climate-induced displacement and human rights, the destruction of cultural heritage 


\subsubsection{The Complaints Procedure}

Whereas there was no agreement to designate the Advisory Committee as the successor to the Sub-Commission, the Complaints Procedure was established based on the former 1503 procedure. Improvements were introduced to ensure that the Procedure emphasizes the impartiality, objectivity, efficiency and victim-oriented character of its work, and the timely response to requests.

The procedure is of a confidential nature. It is not an individual complaint mechanism, as with certain human rights treaties. Under this procedure a person or a group, including NGOs, claiming to be victims of violations of human rights and fundamental freedoms may submit complaints to the Council. The fundamental difference between this procedure and the individual communications' procedures under several treaty bodies lies in the political nature of the Council. It thus addresses consistent patterns of 'gross and reliably attested violations' of human rights and all freedoms occurring in any part of the world and any circumstances. These terms were never - and probably will never be - the subject of consensual agreement on their definition. From the travaux préparatoires of the former so-called ' 1503 procedure' of the Commission which was replaced by the Complaints Procedure, it appears that a 'pattern of gross and reliably attested violations of human rights involve[s] several victims, a certain number of breaches spread over a minimum period of time, which are particularly inhuman or degrading in character'. It is however up to each concerned body to build up its own jurisprudence on a case-by-case manner.

The current Complaints Procedure follows a three-tier approach.

- The Working Group on Communications (WGC), composed of five members appointed by the Advisory Committee, ${ }^{17}$ is the first step

and its effects on the enjoyment of economic, social and cultural rights, the digital transformation and the impact of new technologies on human rights, the promotion of economic, social and cultural rights through jurisdictional means, refugees and internally displaced persons and possible human rights violations in the European Union hotspots camps, right to a remedy and reparation for victims of gross violations of international human rights law and serious violations of international humanitarian law.

17 This is an interesting anomaly. The Council's Resolution 5/1 disconnected entirely the Advisory Committee from what might otherwise have been considered as its predecessor, the SubCommission. However, the members of the Working Groups continue to be selected among members of the Committee in a similar manner to the selection process at the 1503 procedure level. 
in starting the Complaints Procedure. Each member is appointed for a mandate of three years.

- An initial pre-screening of communications received is undertaken jointly by the Chair of the WGC and the Secretariat with a view to screen out the manifestly ill-founded or anonymous ones. Their list is however shared with the WGC for consideration if appropriate. The WGC decides on the admissibility of a communication and assesses the merits of the allegations, particularly as to whether the communication reveals a consistent pattern of gross and reliability attested violations of human rights and fundamental freedoms. It may thus decide to dismiss the communication, keep it under review or channel it to the Working Group on Situations which appears as the third step of the proceedings.

- The Working Group on Situations (WGS) is composed of five members appointed for one year by each regional group. They serve in their personal capacity and their mandate may be renewed once. Based on the recommendations of the WGC, the WGS is requested to present a report to the Council on consistent patterns of gross and reliably attested violations of human rights and fundamental freedoms and to make appropriate recommendations, normally in the form of a draft resolution or decision. It may also keep the case pending or dismiss it.

- Each Working Group meets at least twice a year for five working days each session.

- The reports of the WGS are considered by the plenary of the Council, in closed session, as often as circumstances so require but at least once per year. At the end of the process, the Council may decide to discontinue the consideration of the situation, keep it under review, keep it under review and appoint an independent and highly qualified expert to monitor the situation and report back to the Council, discontinue the review or recommend to OHCHR that it provide additional technical cooperation, capacity-building assistance or advisory services to the State concerned.

It should be mentioned that the Complaints Procedure, at each one of its stages, promotes dialogue of the body (WGC or Council) with the concerned Member States where the violations would have happened. This is particularly the case when the Working Groups decide to keep 
cases under review precisely to trigger dialogue. There is an extremely high rate of responses to the Complaints Procedure requests. Similarly, when a specific case is considered by the Council, delegations from the concerned countries are invited to participate. They do so in substance when the matter is discussed. When decisions are adopted they may take the floor, but only after the decision is adopted.

Although the procedure is by definition of a confidential nature, it is victim-oriented. Hence both the author of the communication and the State concerned are informed of the proceeding when the communication is deemed inadmissible, when it is taken up for consideration by the WGS, when it is kept under review by one of the two working groups or by the Council, and the final outcome.

Of significant importance, whenever the Council has considered a report by the WGS, the Council President discusses it on the following morning, detailing the conclusions reached and the countries considered. This means that despite the fact that the procedure is of a confidential nature, those participating in the procedures are made aware of the situations which are being discussed behind closed doors.

Despite its results, the Complaints Procedure suffers from a lack of understanding about its working methods and the concurrence of other procedures. Complainants may prefer to submit their case to a Special Procedure in the hope of triggering an urgent appeal. The presumed victim could alternatively address a treaty body in the expectation that the case will lead to a final quasi-judicial decision.

The Complaints Procedure also suffers from the confidential nature of its proceedings. Nevertheless, it is rarely mentioned that the percentage of comprehensive responses by concerned States, including concrete action at the domestic level, is extremely high compared with that for other procedures. Also, the level of participation at the plenary level is very high and the outcome of the procedure becomes significant when cases are submitted to it by the Working Group on Situations.

\subsection{Interaction between the various human rights bodies and mechanisms}

As described, there coexist a large variety of extra-conventional mechanisms established by the Council or its predecessor. In parallel, 
further to the latter recommendations, the General Assembly adopted a number of human rights instruments, some of which created treaty bodies. There exist at present 10 such bodies composed of independent experts monitoring the implementation of core international human rights treaties. ${ }^{18}$ Given the number of bodies and mechanisms dealing with human rights matters in the human rights system, one of the most frequently asked questions relates to the interaction, or lack of, between these various conventional and extra-conventional bodies or mechanisms.

There is no obvious response to this question. Depending on circumstances, some would argue that there is ample coordination while others would refute this conclusion. This is probably due to the fact that there are no easily identified criteria enabling cooperation or coordination, which are mostly subjective elements, to be gauged.

In truth, the issues or themes which are being dealt with by these bodies or mechanisms often touch on similar or comparable matters. Immediate examples are the ill-treatment of persons and the deprivation of liberty, the rights of women, the struggle against any form of discrimination, the right to development and the right to life. Many other examples come to mind and it is actually possible to consider that any of the rights enshrined in the Universal Declaration may be dealt with by three or more mechanisms. As far as States are concerned, they may be subjected to reviews or investigations initiated almost simultaneously by several bodies or mechanisms, which represents a serious problem, particularly for small delegations.

This rationale behind the juxtaposition and coexistence of so many different layers is explained below ${ }^{19}$ and almost unavoidable in a multilateral context. Efforts aiming at streamlining some of these bodies or mechanisms have so far been mostly unsuccessful. Much energy is often expended in the negotiation processes, leading eventually to there being no significant change to the existing landscape. It is very hard to envisage in a realistic manner any situation in the future when some of the human rights bodies will be merged or their working methods aligned and fully synchronized. There are simply too many obstacles to such an endeavour, from legal impediments to political or bureaucratic considerations.

18 See https://www.ohchr.org/EN/HRBodies/Pages/TreatyBodies.aspx.

19 See Chapter 2. 
What is striking, however, is that only a few steps have actually been taken in practical terms to ensure an adequate level of cooperation and coordination. At the outset, it should be borne in mind that the co-existence of a variety of bodies or mechanisms is of value, with the repetition of similar or comparable recommendations creating a leitmotif and generating public focus on a particular theme or situation. However, this becomes meaningless if there is no real or genuine coordination, cooperation or even sharing of information between the various actors. Additionally, when this becomes the rule rather than the exception, it defeats the purpose - if there is any.

It is extremely hard not to regret the insufficient level of interaction between all concerned, a fact which is probably linked to the 'silo' mentality prevalent in so many large international or national public or private organizations. However, over the years, genuine but modest efforts have been made to strengthen the complementarity of these bodies and mechanisms, reduce the possible level of duplication and instil practical modalities for cooperation and coordination in their working methods. Some results were achieved, such as for instance the establishment and strengthening over the years of a Coordinating Committee of Special Procedures, the stimulation of dialogues between the Human Rights Council Advisory Council and its parent body as well as the holding of annual meetings of Special Procedures mandate holders and Chairpersons of treaty bodies. However, this is far from the setting up of a practical mechanism of interaction and cooperation.

The picture thus remains of a system which seems, in the author's opinion, to be often missing the various opportunities offered to it to develop proper synergies and coordination. In addition to the 'silo' mentality, it is probably rooted in the conjunction of political and psychological considerations which are often difficult to describe.

It is for instance quite obvious that States may prefer the status quo rather than opening Pandora's box and renegotiating what was agreed years earlier in long and arduous negotiations with the risk of regressing or reaching an unsatisfactory outcome.

Similarly, concerned bodies or mechanisms, obsessed with and overwhelmed by the completion of their mandate, may lose sight of the importance and complementary nature of activities performed by others. Also, it may be extrapolated that independent experts 
composing the various bodies or mechanisms at times display a specific reluctance to change and a related fear of the unknown or their own powers.

In more concrete terms, at least five types of mechanisms coexist which consider the situation of human rights at the country level, namely: (a) the UPR where UN Member States review the situation of all human rights in all countries of the world; (b) the treaty bodies which monitor the implementation of specific human rights in the territory of States parties, either via the reporting or communications procedures; (c) the Special Procedures which report and advise on human rights at the country level from a thematic or country-specific perspective; (d) the various commissions of inquiry, fact-finding missions and investigation mechanisms; and (e) the Complaints Procedure which deals with consistent patterns of gross and reliably attested violations of all human rights in any part of the world. There is however almost no coordination or harmonization processes between them.

In a comparable manner, three mechanisms coexist which consider substantive matters, namely (a) the Human Rights Council Advisory Committee, which operates as a think-tank for the Council, (b) the thematic Special Procedures and (c) the treaty bodies which interpret the provisions of the relevant Covenant or Convention in their general comments or decisions on individual communications.

There is however not a single opportunity for them to meet and exchange information, not to mention develop mutually agreed strategies. Special Procedures mandate holders meet once per year and the Coordinating Committee ensures some form of continuity throughout the year. However, none of the other bodies or mechanisms are participating on a continuing basis. It would appear quite logical that representatives of treaty bodies, commissions of inquiry, the Advisory Committee and the Complaints Procedure (Working Group on Communications) attend the meetings or parts of them and join in the consideration of substantive and organizational matters. This may represent the first step towards generating a culture of communication and coordination among the various components of the human rights system.

Another step would be to systematize exchanges of information and dialogues when substantive human rights provisions are subjected to some form of interpretation or comment by a Committee or a Special 
Rapporteur. Some practical measures may be taken such as the setting up of a virtual platform accessible by all members of treaty bodies, Special Procedures mandate holders and experts of the Advisory Committee. This could be complemented by systematizing the invitation of other mechanisms' experts to any such discussion led by a mechanism, whatever it is.

The UPR is at times perceived as weakening the status of conclusions of treaty bodies and Special Procedures. This comes from what appears to the author as a pure misconception of the modus operandi of the UPR. Indeed, it is considered that their conclusions and recommendations are often included into recommendations by peers in the context of the UPR review. Since the reviewed States are given the opportunity to support or simply note the said recommendations, it is advanced that, by not supporting the treaty bodies' recommendations, this represents a de facto rejection of mandatory documents. ${ }^{20}$

What is not taken into account is that the recommendations made by States in the context of the UPR, although they are often taken from the outcome of the work of treaty bodies or special rapporteurs, almost never quote a specific recommendation. Hence, when noted and not supported by the State under review, the legal effect, if any, is limited to the bilateral relationship between the latter and the State having made the concerned recommendations.

However, considering that an average of two-thirds of all recommendations made in a review are supported by the concerned State and that a significant number of them are directly linked with a treaty body or Special Procedure recommendation, this implies that their content was blessed by the State under review in a formal manner. This strengthens their implementability. Having been supported by the State under review, they may easily be referred to at the domestic level and subjected to discussion and follow-up action. They provide extremely helpful entry points enabling all concerned, from civil society to UN entities, to engage in a substantive manner in the implementation and follow-up process. A proactive approach would thus be for Special Procedures and treaty bodies to build up their follow-up work partly on those recommendations which incorporated their own conclusions. Providing a conceptual basis for such an activity would require appropriate funding and impact on organizational matters. It would,

20 See above, Chapter 1. 
however, maximize the implementation of such important recommendations and uphold the complementary nature of the mechanisms.

Lastly, it is at times regretted that the various mechanisms produce many documents which are not easily accessible, and sometimes partly duplicative and/or of a contradictory nature. Their overwhelming nature is considered as shedding doubt on the possibility of implementing the numerous recommendations they include. However, this corpus of documents also represents the deepest and broadest charting of human rights which currently exists at the universal level. Some efforts have been made to categorize and index these documents, but this remains a complex and somewhat cumbersome exercise. It could be imagined that this could be further refined and fed into user-friendly websites or databases - provided an appropriate level of funding is made available. 